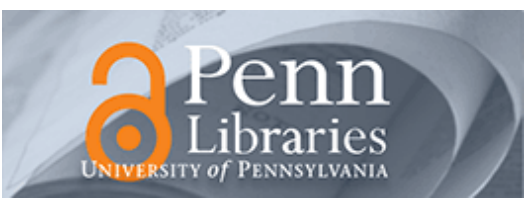

University of Pennsylvania

ScholarlyCommons

9-3-2009

\title{
Tuning hydrogel properties for applications in tissue engineering
}

\author{
Sudhir Khetan \\ University of Pennsylvania, khetans@seas.upenn.edu \\ Cindy Chung \\ University of Pennsylvania, cchung3@seas.upenn.edu \\ Jason A. Burdick \\ University of Pennsylvania, burdick2@seas.upenn.edu
}

Follow this and additional works at: https://repository.upenn.edu/be_papers

\section{Recommended Citation}

Khetan, S., Chung, C., \& Burdick, J. A. (2009). Tuning hydrogel properties for applications in tissue engineering. Retrieved from https://repository.upenn.edu/be_papers/150

Copyright 2009 IEEE. Reprinted from:

Khetan, Sudhir; Chung, Cindy; Burdick, Jason A., "Tuning hydrogel properties for applications in tissue engineering," Engineering in Medicine and Biology Society, 2009. EMBC 2009. Annual International Conference of the IEEE, vol., no., pp.2094-2096, 3-6 Sept. 2009

Publisher URL: http://ieeexplore.iee. org/stamp/stamp.jsp?arnumber=5332484\&isnumber=5332379

This material is posted here with permission of the IEEE. Such permission of the IEEE does not in any way imply IEEE endorsement of any of the University of Pennsylvania's products or services. Internal or personal use of this material is permitted. However, permission to reprint/republish this material for advertising or promotional purposes or for creating new collective works for resale or redistribution must be obtained from the IEEE by writing to pubs-permissions@ieee.org. By choosing to view this document, you agree to all provisions of the copyright laws protecting it.

This paper is posted at ScholarlyCommons. https://repository.upenn.edu/be_papers/150

For more information, please contact repository@pobox.upenn.edu. 


\title{
Tuning hydrogel properties for applications in tissue engineering
}

\begin{abstract}
Biomaterial design is an important component towards tissue engineering applications. There are many parameters that may be adjusted including physical properties (i.e., degradation and mechanics) and chemical properties (e.g., adhesion and cellular interactions). These design components may dictate the success or failure of a tissue engineering approach. Our group is particularly interested in the use of swollen hydrogels as cell carriers. One material that is used to fabricate hydrogels is hyaluronic acid (HA), which is found in many tissues in the body. Here, we show the control over hydrogel degradation, both in the bulk and locally to cells to control both the distribution of extracellular matrix by cells and whether or not a cell spreads in the hydrogels. These signals are important in the final structure and mechanical properties of engineered tissues, and potentially the differentiation of encapsulated stem cells.
\end{abstract}

\section{Comments}

Copyright 2009 IEEE. Reprinted from:

Khetan, Sudhir; Chung, Cindy; Burdick, Jason A., "Tuning hydrogel properties for applications in tissue engineering," Engineering in Medicine and Biology Society, 2009. EMBC 2009. Annual International Conference of the IEEE , vol., no., pp.2094-2096, 3-6 Sept. 2009

Publisher URL: http://ieeexplore.ieee.org/stamp/stamp.jsp?arnumber=5332484\&isnumber=5332379

This material is posted here with permission of the IEEE. Such permission of the IEEE does not in any way imply IEEE endorsement of any of the University of Pennsylvania's products or services. Internal or personal use of this material is permitted. However, permission to reprint/republish this material for advertising or promotional purposes or for creating new collective works for resale or redistribution must be obtained from the IEEE by writing to pubs-permissions@ieee.org. By choosing to view this document, you agree to all provisions of the copyright laws protecting it. 


\title{
Tuning Hydrogel Properties for Applications in Tissue Engineering
}

\author{
Sudhir Khetan, Cindy Chung, and Jason A. Burdick
}

\begin{abstract}
Biomaterial design is an important component towards tissue engineering applications. There are many parameters that may be adjusted including physical properties (i.e., degradation and mechanics) and chemical properties (e.g., adhesion and cellular interactions). These design components may dictate the success or failure of a tissue engineering approach. Our group is particularly interested in the use of swollen hydrogels as cell carriers. One material that is used to fabricate hydrogels is hyaluronic acid (HA), which is found in many tissues in the body. Here, we show the control over hydrogel degradation, both in the bulk and locally to cells to control both the distribution of extracellular matrix by cells and whether or not a cell spreads in the hydrogels. These signals are important in the final structure and mechanical properties of engineered tissues, and potentially the differentiation of encapsulated stem cells.
\end{abstract}

\section{INTRODUCTION}

$\mathrm{T}$ ISSUE engineering is a widely advancing field with a focus on improving the quality of life for patients with damaged or diseased tissues by developing replacement tissues using engineering principles. Typically, combinations of biomaterials, cells, and biological molecules are used synergistically for repair, but this is dependent on the tissue type and native environment [1]. One class of materials being developed includes highlyswollen hydrogels that can be used as cell carriers due to their tunable properties and high water content.

Our laboratory is specifically interested in combinations of mesenchymal stem cells (MSCs) and HA hydrogels for the repair of musculoskeletal tissues (e.g., cartilage). MSCs can be derived from adult tissues, such as bone marrow, and are pluripotent, so they are able to differentiate into a number of cell types, including chondrocytes. MSCs are widely used in tissue engineering and respond to many signals from their microenvironment, including the chemistry, topography, and mechanics of their surroundings [2].

HA is an attractive material for tissue engineering applications since it is a molecule found in many types of tissues, cells can bind to it with surface receptors (e.g., CD44), many cells are able to remodel HA due to the presence of enzymes (i.e., hyaluronidases), and it is easily modified to form crosslinked hydrogels for cell

Manuscript received March 24, 2009. This work was supported in part by NIH grant K22DE015761, an NSF CAREER Award (JAB), and NSF Graduate Research Fellowships (SK and CC). All authors are with the Department of Bioengineering, University of Pennsylvania, 19104 USA (JAB is the corresponding author, phone: 215-898-8537; fax: 215-5732071; e-mail: burdick2@seas.upenn.edu). encapsulation [3]. One specific method for modification and cell encapsulation involves the introduction of reactive methacrylates and subsequent photopolymerization [3]. This technique provides some spatial control over the polymerization and supports viable cell encapsulation. Here, we present further modification of HA hydrogels to increase the functionality of the materials, including hydrogels that have controlled hydrolysis to facilitate ECM distribution and hydrogels that allow for MSC spreading.

\section{MATERIALS AND METHODS}

\section{A. Polymer Synthesis}

HA was modified to give various macromers containing either acrylate or methacrylate reactive groups (Figure 1). Methacrylated HA (MeHA) was synthesized as previously reported [3]. Briefly, methacrylic anhydride (Sigma) was added to a solution of $1 \mathrm{wt} \%$ HA (Lifecore, $\mathrm{MW}=74 \mathrm{kDa}$ ) in deionized water, adjusted to a $\mathrm{pH}$ of 8 with $5 \mathrm{~N} \mathrm{NaOH}$, and reacted on ice for 24 hours. The macromer solution was purified via dialysis (MW cutoff 6-8k) against deionized water for a minimum of 48 hours with repeated changes of water.

Methacrylated lactic acid HA (MeLAHA) and methacrylated caprolactone HA (MeCLHA) were synthesized as previously reported [4], with modifications (Fig. 1A). Briefly, 2-hydroxyethyl methacrylate (HEMA) (Acros organics) was reacted with dl-lactide or $\varepsilon$ caprolactone (Sigma) via a ring opening polymerization in the presence of stannous octoate (Sigma) at $130^{\circ} \mathrm{C}$ for $1 \mathrm{hr}$. The end group was then functionalized into a carboxylic acid (MeLA-COOH, MeCL-COOH) via reaction with succinic anhydride (Sigma) in the presence of $\mathrm{N}$ methylimidazole at $65^{\circ} \mathrm{C}$ in dichloroethane for $13 \mathrm{hrs}$. The sodium salt form of $\mathrm{HA}$ was converted to a tetrabutylammonium (TBA) salt by acidic ion exchange with Dowex $50 \mathrm{~W}$ x 8-200 resin, followed by resin filtration and neutralization with aqueous TBA hydroxide for solubilization in dimethyl sulfoxide (DMSO). MeLA$\mathrm{COOH}$ and $\mathrm{MeCL}-\mathrm{COOH}$ were individually coupled to TBA-HA via esterification reactions with di-t-butyl dicarbonate $\left(\mathrm{BOC}_{2} \mathrm{O}\right)$ as an activating agent with dimethylaminopyridine (DMAP) [5] for $20 \mathrm{hrs}$ at $45^{\circ} \mathrm{C}$. The final products (MeLAHA and MeCLHA) were precipitated and washed in acetone, lyophilized, and stored at $-20^{\circ} \mathrm{C}$ in powder form prior to use.

Acrylated hyaluronic acid (AHA) was synthesized as previously reported [6]. Briefly, 2-hydroxyethyl acrylate (HEA) (Sigma) was functionalized with a carboxylic acid via reaction with succinic anhydride in the presence of $\mathrm{N}$ - 
methylimidazole at $65^{\circ} \mathrm{C}$ in dichloroethane for $13 \mathrm{hrs}$ to form HEA-Succinate (HEA-Suc). HEA-Suc was then coupled with HA-TBA by esterification with $\mathrm{BOC}_{2} \mathrm{O}$ and DMAP for $18 \mathrm{hrs}$ at $45^{\circ} \mathrm{C}$. The reaction mixture was dialyzed extensively against $\mathrm{DI} \mathrm{H}_{2} \mathrm{O}$ and lyophilized to yield the dry product. ${ }^{1} \mathrm{H}$ NMR was used to confirm intermediate and final polymer products.

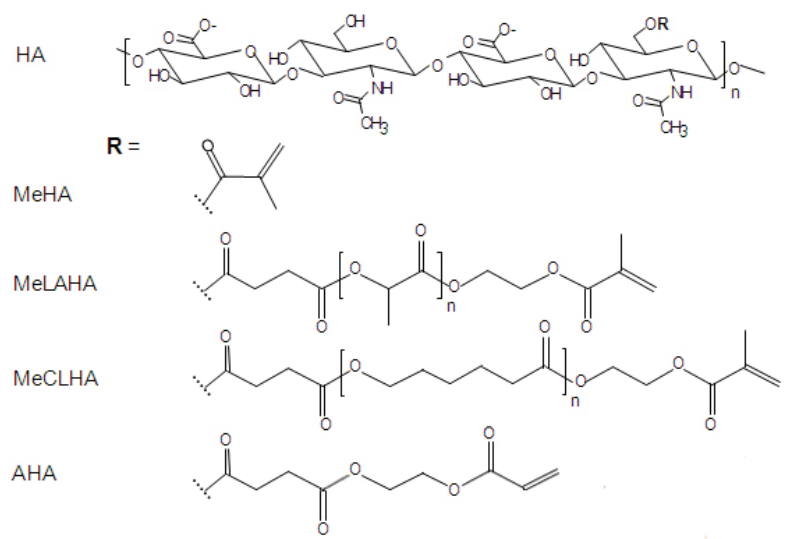

Fig. 1. Chemical structures of MeHA, MeLAHA, MeCLHA, and AHA. Each macromer forms distinct hydrogels with degradation based on the macromer chemistry. Copolymerization of the macromers leads to a wide variety of properties.

\section{B. Hydrogel formation}

For radical crosslinking, lyophilized HA macromers (e.g., MeHA, MeLAHA, MeCLHA and AHA) were dissolved in phosphate buffered saline (PBS) containing $0.05 \mathrm{wt} \%$ 2-methyl-1-[4-(hydroxyethoxy)phenyl]-2-methyl1-propanone (I2959, Ciba) and exposed to UV light for 5 minutes. Addition (via monothiol cell adhesive and dithiol matrix metalloprotease-degradable peptides) crosslinking of AHA was performed in a $0.3 \mathrm{M}$ triethanolamine (TEOA) buffered saline with reaction for 15 minutes at $37^{\circ} \mathrm{C}$.

\section{Hydrogel Characterization and Cell Encapsulation}

For degradation studies, hydrogels were incubated in $1 \mathrm{ml}$ of PBS at $37^{\circ} \mathrm{C}$ for up to 21 days. Degradation products were monitored using a uronic acid assay [7,8], and degradation is plotted as \% uronic acid release. For matrix elaboration, MSCs were photoencapsulated in HA hydrogels (2 $\mathrm{wt} \%$ MeHA, $1 \mathrm{wt} \%$ MeLAHA: $1 \mathrm{wt} \% \mathrm{MeHA}$, and $1 \mathrm{wt} \%$ MeCLHA: $1 \mathrm{wt} \% \mathrm{MeHA}$ ) and cultured in vitro under standard conditions for 14 days in chondrogenic media. Samples were fixed in $10 \%$ formalin for 24 hours, embedded in paraffin, and processed using standard histological procedures. The histological sections $(7 \mu \mathrm{m}$ thick) were stained for chondroitin sulfate distribution using the Vectastain $\mathrm{ABC}$ kit (Vector Labs) and the DAB Substrate kit for peroxidase (Vector Labs). Sections were predigested in $0.5 \mathrm{mg} / \mathrm{ml}$ hyaluronidase for $30 \mathrm{~min}$ at $37^{\circ} \mathrm{C}$ and incubated in $0.5 \mathrm{~N}$ acetic acid for 4 hours at $4^{\circ} \mathrm{C}$ to swell the samples prior to overnight incubation with primary antibodies (mouse monoclonal anti-chondroitin sulfate, Sigma) at a 1:100 dilution.

The degree of spreading of MSCs encapsulated in AHA networks crosslinked either through radical or addition mechanisms was assessed qualitatively, via visualization with a live/dead staining kit (Molecular Probes), and quantitatively, via measurement of cellular aspect ratios. For the latter, the maximum orthogonal width and length of $\mathrm{n} \geq 75$ cells per condition were measured using NIH ImageJ, and the aspect ratio calculated as the longer length divided by the shorter length. Images and measurements were taken after 5 days in standard culture.

\section{Results AND Discussion}

${ }^{1} \mathrm{H}$ NMR confirmed the successful synthesis of hydrolytically degradable HA macromers (MeLAHA and MeCLHA) with $\sim 10.5 \%$ and $\sim 13 \%$ methacrylate modification containing $\sim 3$ and $\sim 3.8$ repeat units of lactic acid and $\varepsilon$-caprolactone between the methacrylate and the HA backbone, respectively. Hydrolytic degradation of these polymers was confirmed with the complete degradation of 2 wt $\%$ MeLAHA and $3 \mathrm{wt} \%$ MeCLHA hydrogels in 5 and 18 days of incubation in PBS at $37^{\circ} \mathrm{C}$ without the addition of exogenous enzymes, while $2 \mathrm{wt} \%$ MeHA hydrogels remained relatively stable up to 21 days with only $\sim 26 \%$ HA released (Fig. 1B).

When photoencapsulated MSCs were cultured in chondrogenic media for 14 days in vitro, the copolymerization of these hydrolytically degradable HA macromers with MeHA resulted in increased ECM deposition and distribution as illustrated in Figure 1C. Cell viability was high in all formulations as assessed with Live/Dead staining. Generally, the photopolymerization does not induce any loss of membrane integrity or mitochondrial activity to the cells during encapsulation. Purely enzymatically degradable MeHA hydrogels can hinder the diffusion of nutrients and ECM proteins within the hydrogel as visualized by the pericellular staining of

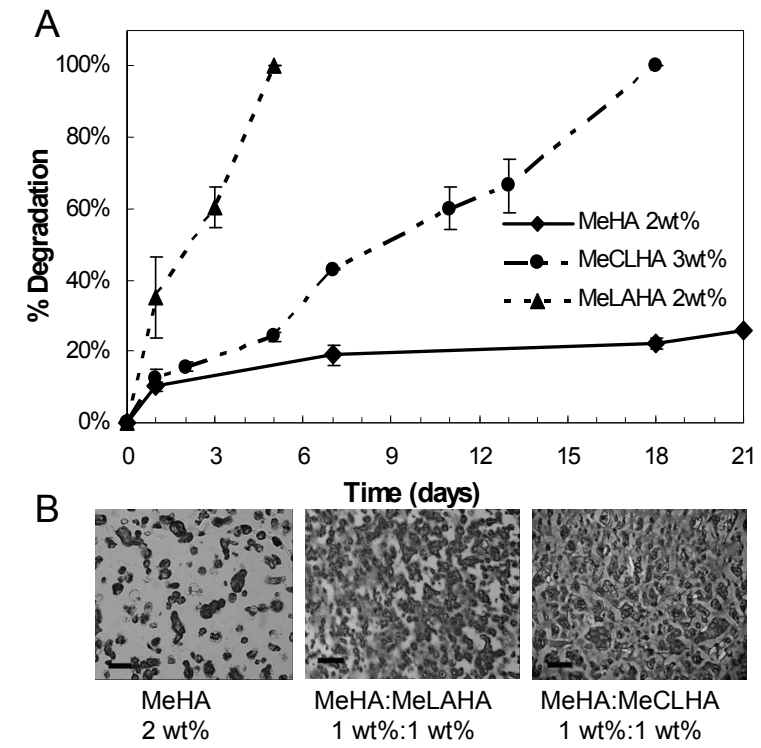

Fig. 2. (A) Degradation of MeHA, MeLAHA, and MeCLHA homopolymer hydrogels in $\mathrm{PBS}$ at $37^{\circ} \mathrm{C}$ over 21 days. (B) Immunohistochemical staining of chondroitin sulfate for $2 \mathrm{wt} \%$ MeHA, $1 \mathrm{wt} \%$ MeHA: $1 \mathrm{wt} \%$ MeLAHA, and $1 \mathrm{wt} \%$ MeHA: $1 \mathrm{wt} \%$ MeCLHA. 
chondroitin sulfate, while the addition of faster hydrolytically degrading components allow for enhanced distribution of ECM proteins, providing a more homogenous distribution of ECM proteins throughout the construct. It is also important to note that the rate of degradation can also influence matrix production and distribution, where a fine balance of hydrogel degradation with ECM deposition must be met to optimize tissue formation.

To further assess the capacity of HA-based scaffolds to control stem cell behavior, AHA was synthesized with $\sim 38 \%$ acrylate modification, as confirmed by ${ }^{1} \mathrm{H}$ NMR. In contrast to methacrylation, acrylation enables chemical (addition) crosslinking with sufficiently short gelation times for uniform distribution of encapsulated cells, while still retaining the ability to undergo crosslinking via the radical mechanism. Figs. $3 \mathrm{a}$ and $3 \mathrm{~b}$ illustrate the good agreement between predicted and observed morphology of MSCs encapsulated in AHA hydrogels crosslinked via each mechanism. Cells in addition-only crosslinked gels secrete MMPs that cleave degradable sites in the crosslinks, creating sufficient local volumes for spreading via focal adhesions with the tethered RGD domains. In contrast, the biologically inert radical crosslinks create mesh sizes in which cells remain completely rounded. These differences are quantified in Fig. 3c; while hMSCs encapsulated in
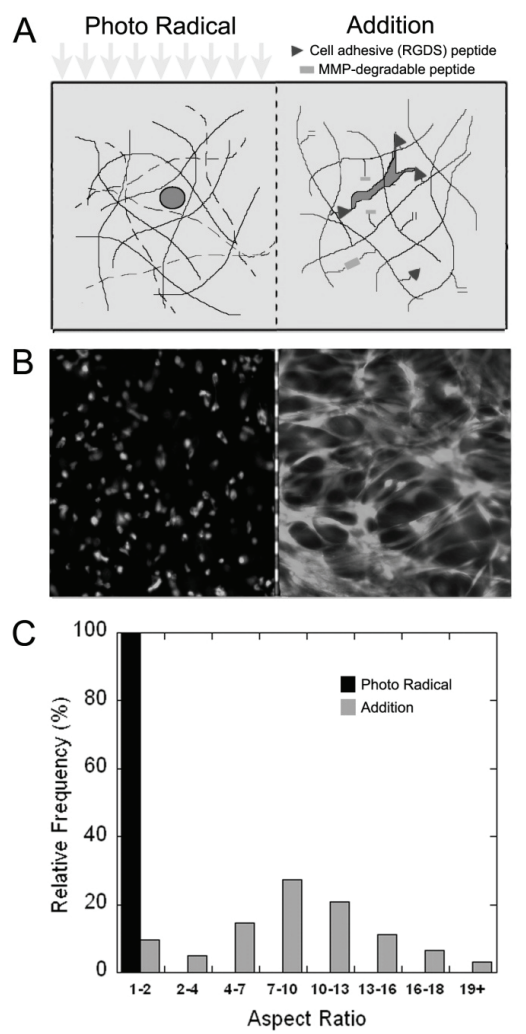

Fig. 3. (A) Schematic of predicted morphology of cells encapsulated in radical and addition crosslinked AHA gels, respectively. (B) Images of encapsulated cells (stained with calcein) in AHA hydrogels formed using radical and addition crosslinking, respectively. (C) Histogram of the cellular aspect ratio (longest to shortest dimension of encapsulated cells) for these same groups. All cultures were for five days. radical-only gels remain completely rounded, with $100 \%$ of cells exhibiting an aspect ratio between 1 and 2, cells in addition-only gels exhibit a distribution toward significantly higher aspect ratios. An advantage to the system is the decoupling of mechanics (control of crosslink density by varying macromer concentration and MMP peptide concentration) and adhesion (control of cell spreading by varying RGD peptide concentration). Both are potential inputs to cellular differentiation [9-11], but are commonly mutually dependent in biomaterial scaffolds. This approach has also been extended to incorporate both radical and addition crosslink types in single gels, with the degree of outgrowth dependent on the ratio of each type used. This allows for spatial control of cellular spreading in a single construct, based on the spatial control afforded with light as a crosslinking mechanism. Taken together, these results illustrate the versatility of AHA and its potential usefulness in controlling stem cell behavior. Towards an implantable material, the spreading of cells could influence not only cellular differentiation, but the integration and interaction with surrounding cells and tissues.

\section{ACKNOWLEDGMENT}

The authors acknowledge the assistance of Dr. Sujata Sahoo and Josh Katz in synthesis and NMR characterization.

\section{REFERENCES}

[1] R. Langer, J.P. Vacanti, “Tissue engineering," Science, vol. 260, pp. 920-926, 1993.

[2] J.A. Burdick, G. Vunjak-Novakovic, "Engineered microenvironments for controlled stem cell differentiation," Tiss. Eng. A, vol. 15, pp. 205219, 2009.

[3] K.A. Smeds, A. Pfister-Serres, D. Miki, K. Dastgheib, M. Inoue, D.L. Hatchell, et al. "Photocrosslinkable polysaccharides for in situ hydrogel formation," J. Biomed. Mater. Res., vol. 54, pp. 115-121, 2001.

[4] S. Sahoo S, C. Chung, S. Khetan, J.A. Burdick, "Hydrolytically degradable hyaluronic acid hydrogels with controlled temporal structures," Biomacromolecules, vol. 9, pp. 1088-1092, 2008.

[5] L.J. Gooßen, A. Döhring A, "A convenient protocol for the esterification of carboxylic acids with alcohols in the presence of di-t-butyl dicarbonate, Synlett., vol. 2, pp. 263-266, 2004.

[6] S. Khetan, J.S. Katz, J.A. Burdick, "Sequential crosslinking to control cellular spreading in 3-dimensional hydrogels," Soft Matter, 2009, in press.

[7] J.A. Burdick, C. Chung, X. Jia, M.A. Randolph, R. Langer, “Controlled degradation and mechanical behavior of photopolymerized hyaluronic acid networks," Biomacromolecules, vol. 6, pp. 386-391, 2005.

[8] T. Bitter, H.M. Muir, "A modified uronic acid carbazole reaction," Anal. Biochem., vol. 4, pp. 330-334, 1962.

[9] F.M. Watt, P.W. Jordan, C.H. O'Neill, "Cell shape controls terminal differentiation of human epidermal keratinocytes," Proc. Nat. Acad. Sci. USA, vol. 85, pp. 5576-5580, 1988.

[10] H. Senechal, J.P. Wahrmann, D. Delain, A. Macieira-Coelho, "Modulation of differentiation in vitro. II. Influence of cell spreading and surface events on myogenesis," In vitro, vol 20, pp. 692-698, 1984.

[11] A.J. Engler, S. Sen, H.L. Sweeney, D.E. Discher, "Matrix elasticity directs stem cell lineage specification," Cell, vol. 126, pp. 677-689, 2006. 